\section{International Scientific Journal Theoretical \& Applied Science}

p-ISSN: 2308-4944 (print) ｅ-ISSN: 2409-0085 (online)

Year: $2016 \quad$ Issue: 3 Volume: 35

Published: $30.03 .2016 \quad$ http://T-Science.org

SECTION 2. Applied mathematics. Mathematical modeling.
Normahmad Ravshanov

Doctor of Technical Sciences, Head of Laboratory,

Centre for the Development of Software and Hardware-Program Complexes, Tashkent, Uzbekistan ravshanzade-09@mail.ru

Daler Sharipov

Senior Researcher, Institute of Mathematics, National University of Uzbekistan, Angren, Uzbekistan qushqor@mail.ru

Farrukh Muradov

Senior Lecturer, Samarkand Branch of Tashkent University of Information Technologies, Samarkand, Uzbekistan

\title{
COMPUTATIONAL EXPERIMENT FOR FORECASTING AND MONITORING THE ENVIRONMENTAL CONDITION OF INDUSTRIAL REGIONS
}

\begin{abstract}
The paper presents a mathematical model and the results of numerical calculations for determining the basic physical parameters, which effect in the transfer process and the diffusion of aerosol emissions in the atmosphere for the purpose of monitoring and forecasting the ecological condition in industrial regions. In deriving the mathematical model of the object of study the main parameters: speed and direction of the wind, which are changed with time, absorption coefficient of aerosol particles in the atmosphere, power and coordinates of sources of emissions of harmful substances, also a significant parameter - the topography of the region are taken into account. Short overview of literatures is outlined, which is related to the problem of mathematical modeling and computational experiment that concerning to the distribution of hazardous substances. On the basis of developed model and algorithm, several numerical calculations in computer were conducted by the authors. The results of calculations are illustrated in graphical form and they are implemented with proper conclusions.

Key words: mathematical model, numerical algorithm, numerical algorithm, computational experiment, transfer and diffusion of hazardous substances, weather and climatic factor, terrain orography.

Language: English

Citation: Ravshanov N, Sharipov D, Muradov F (2016) COMPUTATIONAL EXPERIMENT FOR FORECASTING AND MONITORING THE ENVIRONMENTAL CONDITION OF INDUSTRIAL REGIONS. ISJ Theoretical \& Applied Science, 03 (35): 132-139.

Soi: http://s-o-i.org/1.1/TAS-03-35-22 Doi: crossef http://dx.doi.org/10.15863/TAS.2016.03.35.22
\end{abstract}

\section{INTRODUCTION}

Since the ecology of atmosphere - is one of the most important environmental indicators, there is a need for forecasts impurity concentration in the surface layer of the atmosphere for different time frames. In particular, the practical interest show short-term forecasts relating to the coverage of maximum permissible concentration norm of harmful substances in the projection of structures of new enterprises.

Contamination of the surface layer of the atmosphere and land surface, including the transfer and diffusion of pollutants, and their deposition and concentration - this is a very complex process that subjected to the influence of many factors, including geographical and weather and climatic conditions, which are specific to one or another of the region. Moreover, it is important to take into account the fact that the meteorological conditions are changed during the day and the seasons.

The complexity of the process leads to an integrated approach to the successful achievement of the objective of this research, which consists of developing models, efficient computational algorithms and software tools for the automation of solving the problems of forecasting the ecological state of industrial regions and the adoption of solutions for environmental protection from harmful effects with sufficiently high degree of reliability.

The intense pace of economic development of any country requires the construction and disposition of powerful industrial objects and commercial complexes in different areas depending on the raw capacity and labor supply. Typically, such facilities are constructed in densely populated areas or near them. This imposes special restrictions on the 
placement of objects, which releases harmful substances into the atmosphere by violating the existing environmental condition in this region. In this regard, it is clear that the monitoring and forecasting problem of the transmission process of the diffusion and transfer of harmful substances in the atmospheric boundary layer and the associated acceptance of administrative decisions on the protection of the environment, its protection from technogenic factors are highly relevant, requiring carefully considered decisions.

In addition to industrial objects, the source of emission of harmful particles in the atmosphere is their removal from the soil surface as a result of the turbulent motion of air masses in the atmospheric boundary layer. Every year from the soil surface and the exposed seabed and water tanks and carried into the boundary layer of the atmosphere large amounts of salt dust. In its structure, suspended particles are dominated in the form of aerosols with a impurity of agricultural pesticides, fertilizers and other harmful components of industrial and domestic waste.

It should also be noted that thrown into the atmosphere aerosol particles affect the processes of cloud and precipitation by changing the microstructure of cloud particles and solar radiation and heat transfer processes in the atmosphere, also the temperature conditions of Earth's climate system.

According to climatologists, the impact of ejected particles to the Earth's atmosphere is that aerosols scatter and absorb solar and thermal radiation, altering the radioactive balance of the atmosphere and the underlying surface. Climatic influence of aerosols ejected into the atmosphere industrial facilities causes a change in the radioactive properties (absorption and reflectance) of clouds, and their life time in the atmosphere and change in the relative humidity, which leads to the destruction of the cloud. The presence in the atmosphere spreading aerosol particles leads to a negative effect of radiation, i.e., cooling the Earth's surface.

The above mentioned problem poses the problem for humanity, which requires immediate and indisputable solutions.

The appearance of supercomputers and software has enabled the development of software for the solution of this problem. One of the effective tools that support decision-making on this issue is the development of computer models and conduct computational experiments based on them.

With the usage of computer modeling of transfer process and diffusion of pollutants in the atmospheric boundary layer many studies both applied and fundamental character are carried out. The problem of mathematical modeling of transport and diffusion of pollutants in the process of the atmospheric boundary layer actively solved many scientists.
In particular, the paper [1] is devoted to the creation of an information system for the modeling the process of the spread of hazardous substances in the atmosphere, emitted from industrial objects, using application software «ArcGIS», reflecting on the real state of the air in regions. It should be noted that within the system results can be obtained only at certain points, and they cannot give an adequate picture of the state of the air in the rest area.

In the article [2] a mathematical model of the dynamics and kinetics of aerosol particles in the spread of the atmospheric boundary layer as a multicomponent environment is developed, taking into account the photochemical transformation and formation of aerosols in the troposphere of the northern hemisphere, as well as kinetic processes enucleation, condensation and coagulation.

By the author of article [3] software for the study of the ecological state of the region is developed, placing inflammable objects and their optimization taking into account the terrain and spatial form.

Article [4] is devoted to the development of computer models for monitoring and forecasting the transmission process and the diffusion of aerosol particles into the environment of vehicles. The authors present the results of the numerical implementation of the model on a computer using the finite volume method based on the calculation algorithm developed distributed.

In [5] a mathematical model of the spread of harmful substances in the atmosphere is developed, taking into account the field of wind currents on the basis of the Navier-Stokes equations, taking into account the compressibility and turbulence of the air environment, terrain. SIMPLE-algorithm is used as a numerical method.

A study [6] was based on models developed by the regional agents of the diffusion process, described hydro thermodynamic equation, namely the equation of molecular heat conduction in the active layer of soil, taking into account the heat balance of the underlying surface (water, earth). The comprehensive mathematical model of researchers consists of separate units, which each one is a mathematical model that describes the processes hydro thermodynamic in separate environmental objects. This paper considers the environmental problems associated with the distribution of pollutants from known sources and determined the probable location of the source in an water medium.

The process of transfer and diffusion of aerosol particles in the atmosphere, taking into account different climatic factors and external disturbances is considered in [7]. The article discussed the transport of air pollutants from the source based on the advection of pollutants from the average air flow, mixing polluting atmospheric turbulence and mass diffusion. Also in the paper the study the process of 
distribution of aerosol particles in a variety of physical and mathematical aspects related to the transport and diffusion of pollutants in the atmospheric boundary layer at the weak and strong winds is conducted.

It should be noted that the question of mathematical modeling of pollutant transported by water shows considerable interest. Thus, in [8] the studied the process was modeled as a set of four simple models: the land of water flow, leakage, transfer of pollutants runoff and pollutant deposition (accumulation) on the ground. The developed model is based on the diffusion equation with an additional term on the right side. This model takes into account the influence of topography, lithology territory and the intensity of the contamination rate of absorption of earth surface. The shape, the boundaries and the topology of addressing the problem vary over time and depend on the appearance of dry "islands" surrounded by water.

[9] is devoted to the study of processes of dispersion and diffusion of reactive primary pollutants emitted from elevated line sources in a stable boundary layer of the atmosphere with the wind speed and the generalized quadratic function of the vertical height. For this setting, an exact solution using Laplace transform for linear sources in the atmospheric boundary layer. It takes into account the chemical reaction that occurs as a result of interaction with the air mass, as well as the conversion of gaseous pollutants in the solid particles and their deposition on the surface of the area under consideration.

The authors of [10-13] developed software solutions for the multi-component ambient air movement task considering the transfer and diffusion of pollutants in the atmosphere, changes in the thermal regime of the atmosphere, the phase transition, as well as the influence of vegetation.

In [14] the process of dissemination of harmful substances, taking into account changes in the concentration of aerosol particles in the atmosphere and seasonal changes in seasons, and in [15] developed a mathematical model, numerical algorithms and software for computational experiment on the computer.

Article [16] is devoted to modeling of diffusion and transfer process of the particles in the atmosphere, taking into account changes in hydrometrological parameters of the atmosphere.

The process of optimal placement of industrial objects in the regions to support the sanitary norms was considered in [17].

\section{PROBLEM FORMULATION}

Consider the one-dimensional equation of transfer and diffusion of hazardous substances in the atmosphere, taking into account orography of the ground as the first boundary value problem [18-21]

$$
\begin{aligned}
& \frac{\partial \varphi(x, t)}{\partial t}+u \frac{\partial \varphi(x, t) h(x)}{\partial x}+ \\
& +\sigma(x, t) \varphi(x, t) h(x)= \\
& =\mu \frac{\partial^{2} \varphi(x, t) h(x)}{\partial x^{2}}+f(x, t),(x, t) \in D,
\end{aligned}
$$

with the following conditions

$$
\left.\begin{array}{c}
\varphi(x, 0)=\stackrel{0}{ }, \text { when } t=0 \\
0<x<L_{x}, \\
\varphi(0, t)=v_{1}, \text { when } x=0 \\
\varphi(\ell, t)=v_{2}, \text { when } x=L .
\end{array}\right\}
$$

Here $\varphi$ - the aerosol; $u$ - wind speed; $\sigma$ absorption coefficient; $f(x, t)$ - the power of the source; $\mu$ - the diffusion coefficient; $h$-option to define the terrain; $v_{1}, v_{2}$ - function depending on $\mathrm{x}$.

For each layer of the model the factor $h(0 \leq h \leq 1)$ is introduced, determining the degree of blocking air flow (Fig. 1).

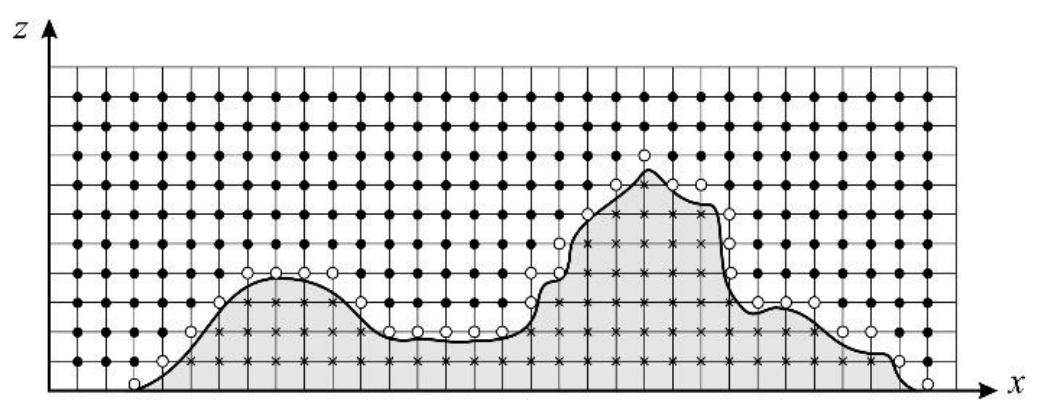

Figure 1 - The relief of terrain along the area of aerosol transfer emissions

$$
\text { ○ - } h=\frac{\eta-z_{K-0,5}}{\Delta z}, \mathbf{x}-h=0, \bullet-h=1 \text {. }
$$




\begin{tabular}{|c|c|c|c|c|c|c|}
\hline Impact Factor: & $\begin{array}{l}\text { ISRA (India) } \\
\text { ISI (Dubai, UAE } \\
\text { GIF (Australia) } \\
\text { JIF }\end{array}$ & $\begin{array}{l}=1.344 \\
=0.829 \\
=0.564 \\
=1.500\end{array}$ & $\begin{array}{l}\text { SIS (USA) } \\
\text { PИНЦ (Russia } \\
\text { ESJI (KZ) } \\
\text { SJIF (Morocco }\end{array}$ & $\begin{array}{r}=\mathbf{0 . 9 1 2} \\
=\mathbf{0 . 1 7 9} \\
=\mathbf{1 . 0 4 2} \\
=\mathbf{2 . 0 3 1}\end{array}$ & $\begin{array}{l}\text { ICV (Poland) } \\
\text { PIF (India) } \\
\text { IBI (India) }\end{array}$ & $\begin{array}{l}=6.630 \\
=1.940 \\
=4.260\end{array}$ \\
\hline
\end{tabular}

\section{METHOD OF SOLUTION}

From the statement of the problem (1) - (3) it implied that it is difficult to obtain an analytical solution. Thus, for the numerical integration of tasks we developed a numerical algorithm based on differential operators replaced by a finite-difference [22-23].

\section{THE DISCUSSION OF THE RESULTS}

For research, forecasting and monitoring the environmental condition of industrial regions and making administrative decisions, a series of numerical calculations on a computer were conducted by setting different values for the parameters of transfer process of harmful substances in the atmospheric boundary layer. The results of numerical calculations are presented in Fig. 2-10.

The numerical calculations showed that (curves in Fig. 2), the main parameter that affects the process of transport and diffusion of pollutants in the atmosphere, is the absorption coefficient of harmful substances in the atmosphere, which depends on the moisture content in the atmosphere and varies by time of day and season.

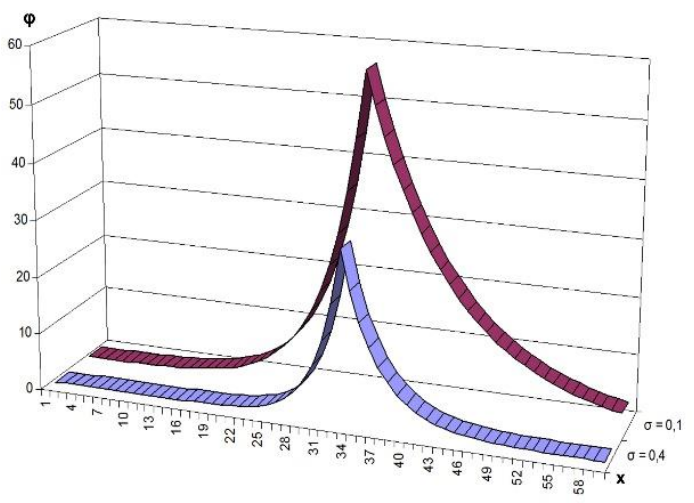

Figure 2 - Changes in the concentration of substances in the air at different values of the absorption coefficient of harmful particles $(\sigma=0,1$ and $\sigma=0,4)$.

Another significant physical component, which plays an important role in the spread of aerosol particles in the atmosphere, is the wind speed in three areas in the atmospheric boundary layer (Fig. 3). As follows from the curves in Fig. 3, with the growth rates of the air mass in the horizontal process intensifies the spread of harmful substances, while the unstable wind stratification for a small period of time there is a sharp change in the concentration of harmful substances in the atmosphere. From the curves in Fig. 3, it is clear that the change in the concentration of pollutants in the atmosphere occurs mainly due to convective particle transfer.

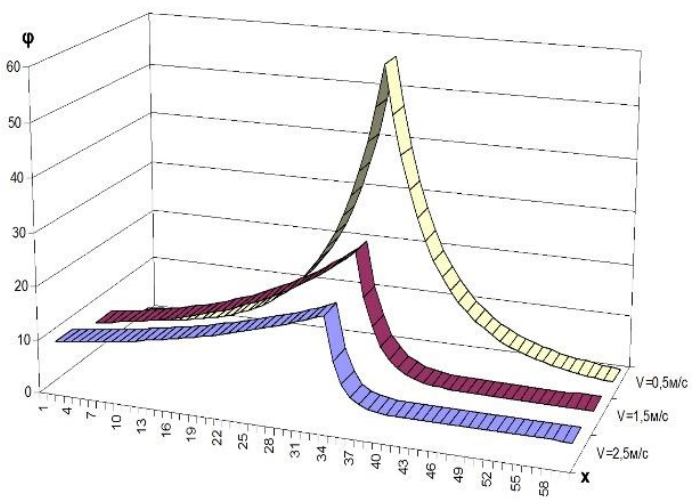

Figure 3 - Changes in the concentration of substances in the atmosphere at various values of the wind velocity in the boundary layer of the atmosphere $(\mathrm{V}=0.5 \mathrm{~m} / \mathrm{s}, \mathrm{V}=1.5 \mathrm{~m} / \mathrm{s}, \mathrm{V}=2.5 \mathrm{~m} / \mathrm{s})$.

Fig. 4 shows the results of numerical calculation on the computer, changes of the concentration of harmful substances in the atmosphere at the south-west and south-west direction of the wind. The numerical calculation carried out at the positive and negative horizontal wind speed $(\mathrm{V}=2,5 \mathrm{~m} / \mathrm{s}, \mathrm{V}=-2,5 \mathrm{~m} / \mathrm{s})$. From the curves in Fig. 4 it is clear that the transfer of pollutants from the source to occur symmetrically in the left and right (in the direction of the wind). 


\begin{tabular}{l|lrl|l|ll} 
& ISRA (India) & $=\mathbf{1 . 3 4 4}$ & SIS (USA) & $=\mathbf{0 . 9 1 2}$ & ICV (Poland) & $=\mathbf{6 . 6 3 0}$ \\
Impact Factor: & ISI (Dubai, UAE) $=\mathbf{0 . 8 2 9}$ & PUHU (Russia) $=\mathbf{0 . 1 7 9}$ & PIF (India) & $=\mathbf{1 . 9 4 0}$ \\
& GIF (Australia) & $\mathbf{0 . 5 6 4}$ & ESJI (KZ) & $=\mathbf{1 . 0 4 2}$ & IBI (India) & $\mathbf{4 . 2 6 0}$
\end{tabular}

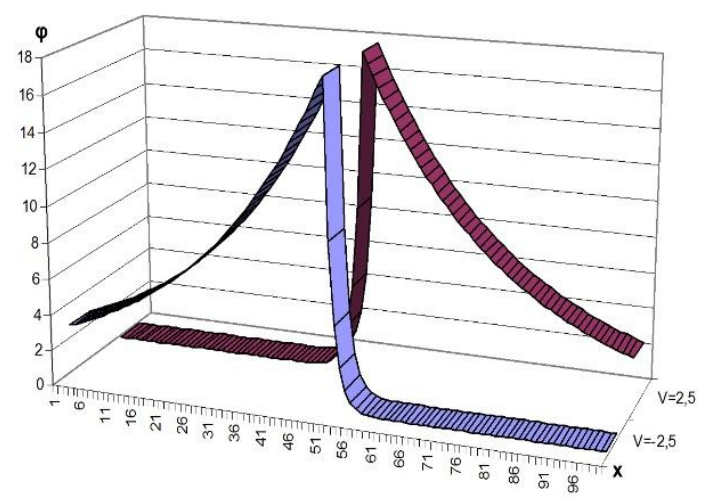

Figure 4 - Changes in the concentration of substances in the atmosphere in the southwest and southwestern direction of the wind

The numerical calculations in computer have shown that the growth of the concentration of aerosol particles in the atmosphere is the power and the coordinates of the emission source (Fig. 5). This is especially noticeable when the air mass is with moderate speed.

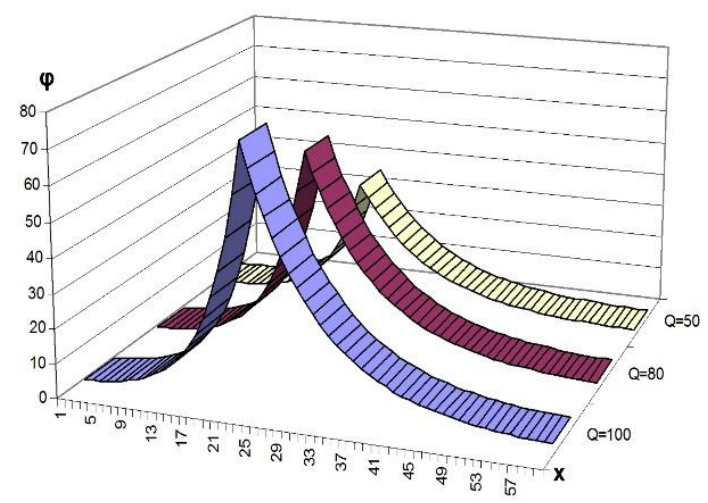

Fig. 5. Distribution of concentration of harmful substances in the atmosphere at different values of the source's power

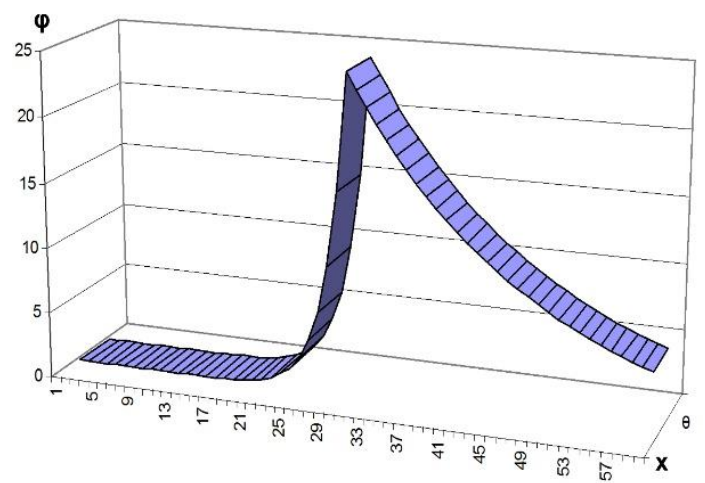

Figure 6 - The concentration of aerosol in the atmosphere at $t=10$ hours. (with the wind speed $V=1,7$ $\mathrm{m} / \mathrm{s}$ during 6 hours. The blowing in the south-west direction and at a speed $V=1,5 \mathrm{~m} / \mathrm{s}$ during 4 hours in the south-west direction).

Fig. 6 shows the change of concentration of aerosol particles in the atmosphere at $\mathrm{t}=10$ hours. When the wind speed is $\mathrm{V}=1,7 \mathrm{~m} / \mathrm{s}$ for 6 hours. The blowing in a southwest direction, and a speed $\mathrm{V}$ $=1,5 \mathrm{~m} / \mathrm{s}$ for 4 hours in the south-west direction. Based on the results it is clear that a change in the concentration of harmful substances play an important role wind speed and direction, as well as their duration.

In the absence of wind (air mass resting condition) (Fig. 7), the concentration of harmful substances is distributed symmetrically in four directions with respect to the emission source. The numerical calculations have shown that the 


\begin{tabular}{|c|c|c|c|c|c|c|}
\hline Impact Factor: & $\begin{array}{l}\text { ISRA (India) } \\
\text { ISI (Dubai, UAF } \\
\text { GIF (Australia) } \\
\text { JIF }\end{array}$ & $\begin{array}{l}=1.344 \\
=0.829 \\
=0.564 \\
=1.500\end{array}$ & $\begin{array}{l}\text { SIS (USA) } \\
\text { PИНЦ (Russia) } \\
\text { ESJI (KZ) } \\
\text { SJIF (Morocco) }\end{array}$ & $\begin{array}{l}=0.912 \\
=0.179 \\
=1.042 \\
=2.031\end{array}$ & $\begin{array}{l}\text { ICV (Poland) } \\
\text { PIF (India) } \\
\text { IBI (India) }\end{array}$ & $\begin{array}{l}=6.630 \\
=1.940 \\
=4.260\end{array}$ \\
\hline
\end{tabular}

concentration of particulate matter will accumulate around the source, depending on the power source and the release duration.

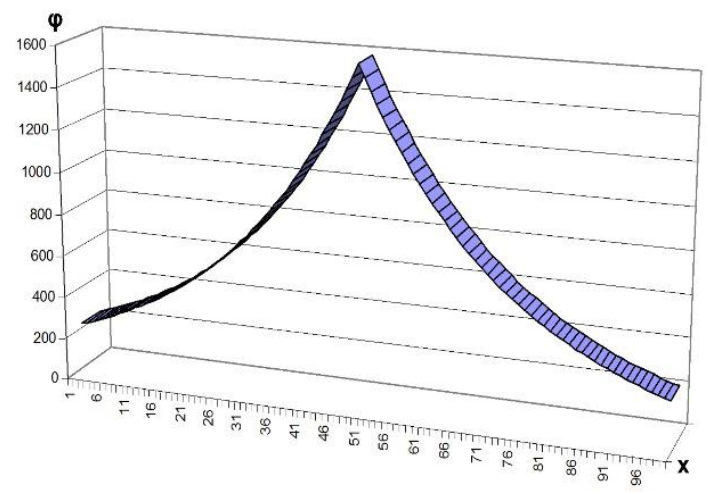

Figure 7 - Changing the concentration of harmful substances in the atmosphere in the absence of wind in the atmosphere.

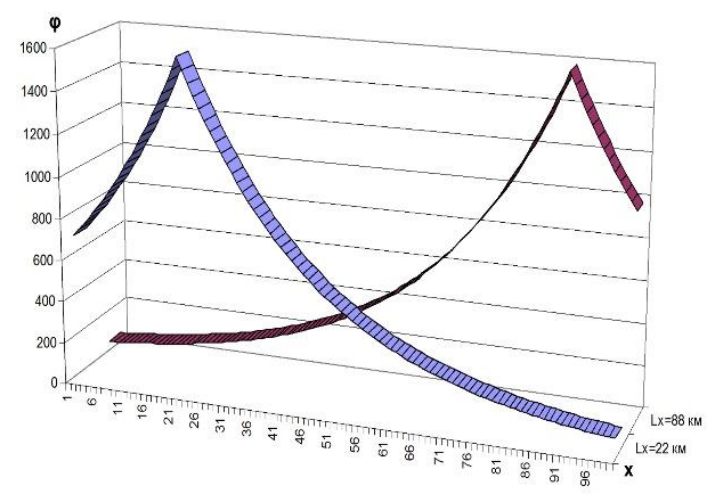

Figure 8 - Changes in the concentration of harmful substances in the atmosphere, depending on the location of emission sources.

Fig. 8 shows changes in the concentration of harmful substances in length when the springs are located at the beginning and end (for $L x=22 \mathrm{~km}, L x$ $=88 \mathrm{~km}$ ) addressing tasks. As seen from the curves in Fig. 8, the concentration of hazardous substances decreases exponentially along the length of the region considered solutions at moderate atmospheric air mass flow rate. Maximum accumulation of harmful substances is expected around the source of emission of the aerosol particles.
Numerical calculations were performed for the case where there are three sources of emission of harmful substances with the same capacity (Fig. 9). Analysis of the results of numerical experiments showed that the essential physical parameters acting on the change in the concentration of harmful substances in the atmosphere, are the ratio of the particles of the absorption and flow rate of the air mass of the atmosphere.

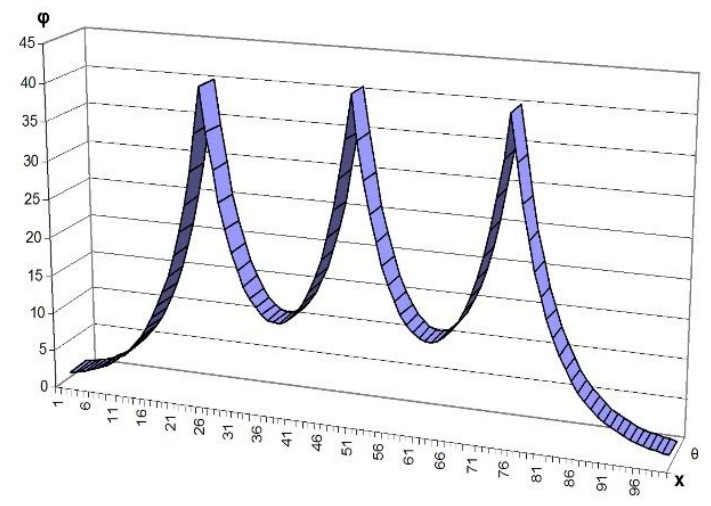

Figure 9 - Change of the concentration of hazardous substances in the atmosphere depending on the location of particulate emission sources (three sources with power equals to 50). 


\begin{tabular}{l|lrl|l|ll} 
& ISRA (India) & $=\mathbf{1 . 3 4 4}$ & SIS (USA) & $=\mathbf{0 . 9 1 2}$ & ICV (Poland) & $=\mathbf{6 . 6 3 0}$ \\
Impact Factor: & ISI (Dubai, UAE) $=\mathbf{0 . 8 2 9}$ & PUHU (Russia) $=\mathbf{0 . 1 7 9}$ & PIF (India) & $=\mathbf{1 . 9 4 0}$ \\
& GIF (Australia) & $\mathbf{0 . 5 6 4}$ & ESJI (KZ) & $=\mathbf{1 . 0 4 2}$ & IBI (India) & $\mathbf{4 . 2 6 0}$
\end{tabular}

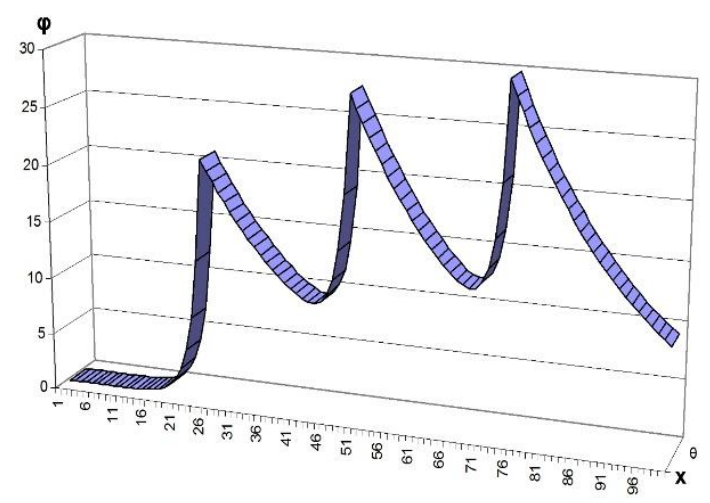

Figure 10 - Change of the concentration of hazardous substances in the atmosphere depending on the locations of the ejection of the aerosol particles (three source with power equals to 50 at a wind velocity of $\mathrm{V}$ $=2,5 \mathrm{~m} / \mathrm{s}$ ).

Numerical calculation on the process of transfer and diffusion of pollutants in the atmosphere during operation of the three sources to be equivalent pollutant emissions capacities showed that the total accumulation of aerosol particles occurs in an area where the third source is located, when the wind is blowing at a speed of $\mathrm{V}=2,5$ to $37 \mathrm{~m} / \mathrm{s}$ in the direction of the source (Fig.10).

\section{CONCLUSION}

The analysis of numerical experiments on the computer showed that:

- significant parameters which influence the process of transfer and diffusion of harmful particles in the atmosphere are, firstly, the absorption coefficient of harmful substances into the atmosphere, which is dependent on the moisture content in the atmosphere and varies by time of day and time of year; secondly, wind speed and direction, as well as their duration; thirdly, the power sources of emission of harmful particulate matter;

- the maximum accumulation of harmful substances in the aerosol particle emission area occurs where there are moderate winds or its absence;
- when there is no wind (air mass resting condition) the concentration of harmful substances is distributed symmetrically in four directions with respect to the emission source;

- results of modeling revealed that a significant role in changing the speed and direction of winds play uplands - hill or mountain ranges located in open landscape, recorded in the model parameter $h(x)$. Above the uplands, the wind speed is higher than the surrounding plain area. Since the high pressure area actually extends some distance up the hill, the wind changes its direction before reaching it. If the air mass meets a steep hill with a rough surface, the wind speed increases dramatically, this leads to an increase in the coefficient of turbulence. Wind speed increases with the difference of atmospheric pressure and air velocity falls in the ground due to the friction of the underlying surface roughness;

- it is found that an increase in capacity of aerosol generators area of the region grows where the concentration exceeds the permissible sanitary norms, and when the wind is in unstable stratification, the area of distribution of harmful substances, has a spiked character - maximized in a short period of time.

\section{References:}

1. Smirnov EA (2011) Information system for the modeling of air pollution using ArcGIS // Actual questions of technical sciences: Materials Intern. scientific. Conf. - Perm, 2011. - pp. 27-31.

2. Aloyan AE (2002) The dynamics and kinetics of gas pollutants and aerosols in the atmosphere. - Moscow: INM RAS, 2002. - 201 p.
3. Chub AI (2013) Mathematical model of optimization problem placing inflammable objects based on topography layout area // Radioelektronika, computer science, upravlinnya release. - 2013. - № 1. - pp. 88-93.

4. Sukhinov AI, Gadelshin VK, Lyubomischenko DS (2009) Mathematical model of the spread of harmful emissions from motor vehicles, based on control volume method and its parallel implementation on a cluster of distributed 


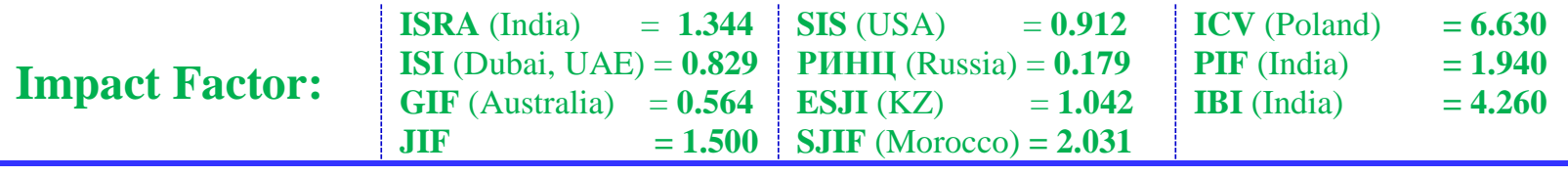

computing // Southern Federal University. Technical science. - 2009. - № 2. - Volume 91. - pp. 8-14

5. Gadelshin VK, Lyubomischenko DS, Sukhinov AI (2010) Mathematical modeling of the field of wind currents and distribution of contaminants in city terrain based $\mathrm{k}-\varepsilon$ turbulence model // Proceedings of the Southern Federal University. Technical science. - 2010. № 6. - Volume 107. - pp. 48-67.

6. Kordzadze A (2007) Mathematical modelling of dynamical and ecological processes in the system sea-land-atmosphere // Air, Water and Soil Quality Modelling for Risk and Impact Assessment. - 2007. - pp. 181-193.

7. Sharan M, Gopalakrishnan SG (2003) Mathematical modeling of diffusion and transport of pollutants in the atmospheric boundary layer // January pure and applied geophysics. - 2003. - Vol. 160. - Issue 1-2. - pp. 357-394.

8. Gitis VG, Petrova EN, Pirogov SA, Yurkov EF (2007) Mathematical modeling of the pollutants overland flow and transport // Automation and Remote Control. - 2007. - Vol. 68. - Issue 9. pp. 1643-1653.

9. Khan Y, Shekhu M, Sulochana C (2013) Mathematical model for dispersion and diffusion of chemically reactive pollutants from various sources into a boundary layer with dry deposition // Engineering Computations. - 2013. - Vol. 30. - Issue 5. - pp. 707 - 727.

10. Sukhinov AI, Chistyakov AE, Hachun DS (2011) Mathematical modeling of motion of a multicomponent air and transport of pollutants // Southern Federal University. Technical science. - 2011. - № 8. - pp. 73-79.

11. Chistyakov AE, Hachunts DS (2013) The problem of motion of a multicomponent air quality in view of vaporization and condensation // Southern Federal University. Technical science. - 2013. - № 4. - pp. 87-98.

12. Sukhinov AI, Hachunts DS (2013) Software implementation of a two-dimensional problem of ambient air movement // Southern Federal University. Technical science. - 2013. - № 4. pp. $15-20$.

13. Chistyakov AE (2009) The three-dimensional model of the motion of water environment in the Azov Sea, taking into account transport of salt and heat // Southern Federal University. Technical science. - 2009. - № 8. - pp. 75-82.

14. Morant JL, González RM, José RS, Pérez JL (2008) A seasonal and yearly pollution study by using wrf / chem and wrf-cmaq nested with ccsm3 global model // Hrvatski Meteoroloski
Casopis. Croatian Meteorological Journal. 2008. - T. 43. Part 1. - pp. 259-263.

15. Gaydos TM, Koo B, Pandis SN, Chock DP (2003) Development and application of an efficient moving sectional approach for the solution of the atmospheric aerosol condensation / evaporation equations // Atmospheric Environment. - 2003. - T. 37. № 23. - pp. 3303-3316.

16. Hassan OAB (2003) A value-focused thinking approach for the environmental management of buildings construction // Journal of Environmental Assessment Policy and Management. - 2003. - T. 5. № 2. - pp.247-261.

17. Haurie A, Kubler JJE, Clappier A, Van Den Bergh HA (2004) Met modeling approach for integrated assessment of air quality policies // Environmental Modeling and Assessment. 2004. - V. 9. № 1. - pp. 1-12.

18. Ravshanov N, Shertaev M, Toshtemirova N (2015) Mathematical Model for the Study and Forecast of the Concentration of Harmful Substances in the Atmosphere // American Journal of Modeling and Optimization. - 2015. Vol. 3. - № 2. - pp. 35-39.

19. Ravshanov N, Sharipov DK, Akhmedov D (2015) Modeling pollution process environment, taking into account the terrain climatic factors // Information technology modeling and management - Voronezh, 2015. №3. - pp. 222-235.

20. Sharipov DK (2013) Development of mathematical software aerosol transport and diffusion of the atmospheric emissions // European Applied Sciences. - 2013. -Vol. 1. № 1. - pp. 233-240.

21. Ravshanov N, Sharipov D (2013) A physical splitting method for the solution of a problem of spread of harmful substances into the atmosphere // Intellectual Archive. - 2013. Vol. 2. - № 6. - pp. 27-39.

22. Sharipov D (2016) A Mathematical Model and Computational Experiment for the Study and Forecast of the Concentration of Harmful Substances in the Atmosphere // American Journal of Computation, Communication and Control. - 2016. - № 2 (6). - pp. 48-54.

23. Ravshanov N, Sharipov DK, Narzullaeva N (2016) advanced mathematical model of the processes of transfer and diffusion of pollutants in the surface atmospheric boundary layer // Scientific Review. Technical science. - Penza: Natural Science Academy, 2016. - № 4. - pp. 49-59. 